\title{
Distribution of Cortical Bone in Bovine Limbs
}

\author{
Sung-Jin $\mathrm{CHOI}^{3)}$, Jong-Il LEE ${ }^{2)}$, Nam-Soo $\mathrm{KIM}^{1)}$ and In-Hyuk $\mathrm{CHOI}^{1) *}$ \\ ${ }^{1)}$ College of Veterinary Medicine, Chonbuk National University, Jeonju 561-756, ${ }^{2)}$ Bio-Safety Research Institute, Chonbuk National \\ University, Jeonju 561-756, Republic of Korea and ${ }^{3}$ Graduate School of Agricultural and Life Sciences, The University of Tokyo, Tokyo \\ 113-8657, Japan
}

(Received 18 January 2006/Accepted 18 April 2006)

ABSTRACT. Xenogenic bone grafts have been widely researched because they are not limited in terms of volume and size like autogenous and allogenic grafts, and the favored bone for xenografts is bovine bone. However, the efficacy of cortical bone from bovine limb for xenografts is not clearly known. In this study, the distribution of cortical bone in bovine humerus, radius, femur, and tibia were investigated. Each experimental bone was split longitudinally with a bone saw and bone marrow and cancellous bone were removed. The thicknesses of cortical layers in sample diaphyses were measured at $1 \mathrm{~cm}$ intervals using a micrometer. The mean lengths of cortical portions were; humerus $14.7 \pm 2.3 \mathrm{~cm}$, radius $19.0 \pm 2.6 \mathrm{~cm}$, femur $19.0 \pm 3.2 \mathrm{~cm}$, and tibia $23.0 \pm 3.1 \mathrm{~cm}$. Thickest cortical bone was found at the distal caudal metaphysis of the humerus, the proximal caudal metaphysis of the radius, the craniolateral and caudomedial midshaft of the femur and the lateral and medial midshaft of tibia. The mean surface areas of cortical bone were humerus $187.4 \pm 15.44$ $\mathrm{cm}^{2}$, radius $229.2 \pm 43.31 \mathrm{~cm}^{2}$, femur $295.8 \pm 8.93 \mathrm{~cm}^{2}$, and tibia $290.0 \pm 30.44 \mathrm{~cm}^{2}$. And, mean volumes of cortical bone were humerus $149.42 \pm 15.35 \mathrm{~cm}^{3}$, radius $166.26 \pm 20.02 \mathrm{~cm}^{3}$, in femur $220.45 \pm 22.73 \mathrm{~cm}^{3}$, and tibia $214.89 \pm 20.05 \mathrm{~cm}^{3}$. The results of this study can be used to produce cortical bone-based plates and screws.

KEY WORDS: bovine, distribution of cortical bone, xenografts.

J. Vet. Med. Sci. 68(9): 915-921, 2006

The various types of internal orthopedic fixateurs for fractures include bone plate, bone screw, intramedullary pins, and orthopedic wire made of stainless steel, cobaltchromium, titanium, and different alloys. In particular, metal internal fixateurs have better strength and efficiency for fracture fixation, but if when installed long term they increase stress and fatigue of fixed bone and may result in refracture [5]. Therefore, additional surgery is required for removing internal fixateurs, which increase patient expense and pain. Various studies have been undertaken to develop internal orthopedic fixateurs that are absorbed to avoid additional removal surgery, and these have resulted in the developments of polymeric substances such as polyglycolide (PGA), polylactide (PLA), polydioxanone (PDS), and polylevolactic acid (PLLA) [16]. However, fixateurs produced from polymerized materials have the disadvantages of early absorption and insufficient strength, and therefore fail to fix fractures durably and are applicable to limited area such as the phalanges and skull, which require less strength. The biomechanical strength of cortical bone is such that a short segment of tibia diaphysis is able to carry the weight of a compact car, and a standard $4.5 \mathrm{~mm}$ cortex screw anchored in a cortex can withstand about $250 \mathrm{~kg}$ [2].

Allografts and xenografts have been widely applied as bone grafts since Urist [18] proved that non-vital cortical bone contained bone morphogenetic protein (BMP). Because allografts are limited due to donor bone insufficiencies, xenografts have been extensively researched $[11,14]$ and bovine bones are favored for xenografts $[3,14,17]$.

\footnotetext{
* Correspondence to: Choi,, I.-H., College of Veterinary Medicine, Chonbuk National University, Jeonju 561-756, Republic of Korea.
}

Bovine bones offer an unlimited supply and the BMP in bovine cortical bone is considered non-species specific. Therefore, BMP from bovine bone has already been commercialization by bone and tissue banks $[15,17]$. For these reasons, many researchers have been interested in the use of bovine bone, which also has sufficient strength for the manufacture of internal fixateurs for bone fractures.

Bone withstands bodyweight and protects organs. In particular, bones of the limbs in animals cooperate with muscles, ligaments, joints, hooves, palms and soles to support the bodyweight and dynamic loadings [8]. According to the size, activity and habits of an animal, these dynamic loadings to limbs vary considerably, and the shapes of bones in limbs and the distributions of cortical bone thickness, which are a part of disposing to withstand bodyweight and dynamic loading, are extremely variable in nature $[1,4,6-8$, $10,12,13,19,20]$. The long bones of bovine limbs have been harvested to make internal fixateurs or implants for bone grafts, and have been reported to contain a thick and plentiful cortical layer; however, the thickness of the cortical layer and its distribution in the long bones of bovine limbs has not been reported upon in terms of its effectiveness as a source of implants or fixateurs.

In this study we examined the thickness and distribution of bovine long bone cortical layers. The data presented can be used as basic statistical data, or to improve the amount of cortical bone extracted from long bones of bovine limbs for the production of internal xenograft fixateurs or implants.

\section{MATERIALS AND METHODS}

Preparation of samples for measuring cortical layer 

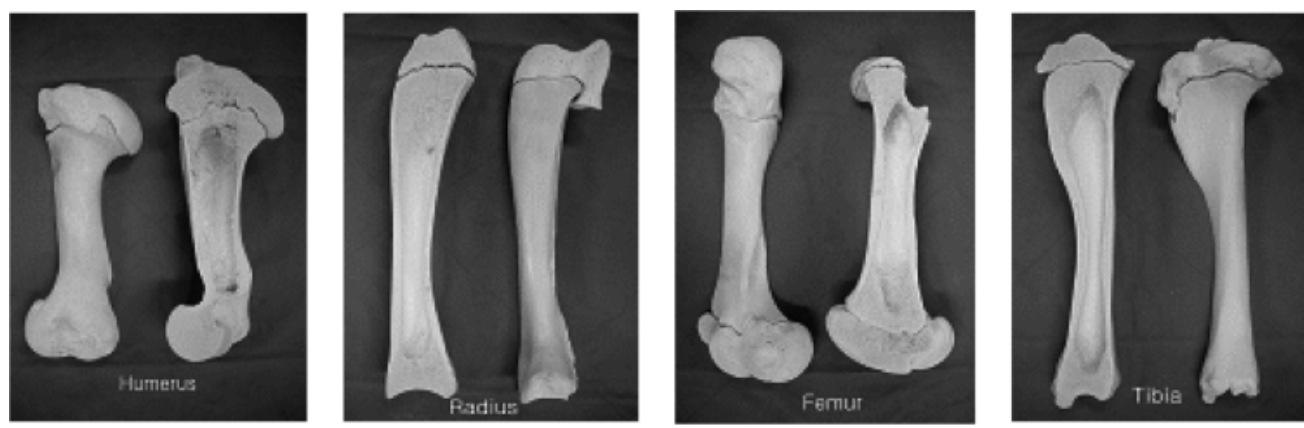

Fig. 1. Longitudinal section by the cranial midline of long bone.
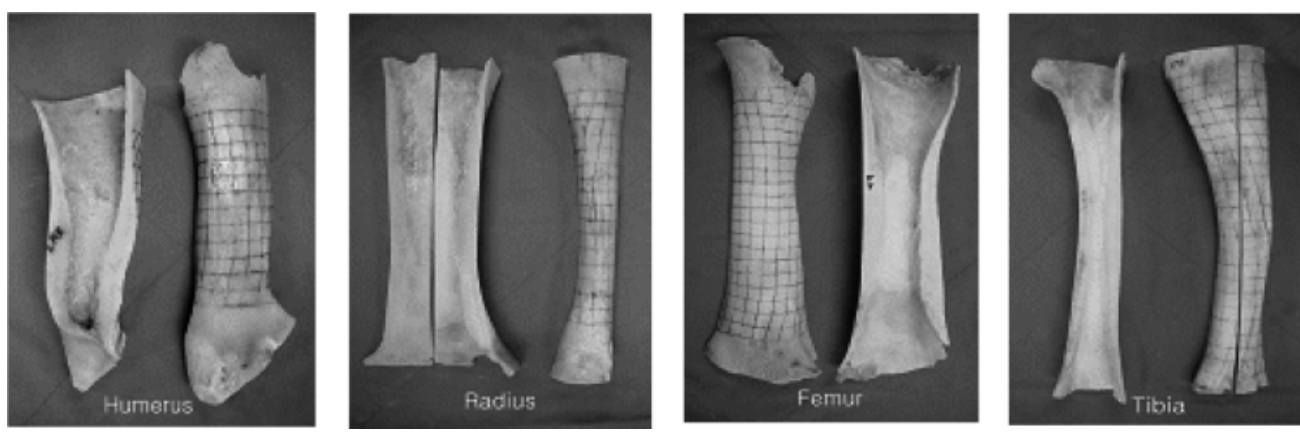

Fig. 2. Preparations for measuring by cutting off epiphyses, removing cancellous and marrow tissue, and drawing a $1 \mathrm{~cm}$ interval grid on the surface.

thicknesses: Five humeri, radii, femurs, and tibiae were used in this study, which were from imported beef cattle aged from one to two years of either sex. Epiphyses composed of cancellous bone on the experimental bone samples were removed for cortical layer measurements and samples were cut perpendicularly through the midline of the cranial face to remove bone marrow and cancellous tissue in the diaphysis (Fig. 1). Cancellous bone was removed by using burs (Fig. 2).

Measurement of cortical layer thickness: The portion measured was the diaphysis without the epiphyses, which has a cancellous articular cartilage, and cut off the margin of metaphyses in which cortical layer is below $1 \mathrm{~mm}$. Samples with removed cancellous and marrow tissue were divided into medial and lateral portions by the midline of the cranial face. A $1 \mathrm{~cm}$ interval grid was constructed on sample surfaces (Fig. 2) and cortical layer thicknesses were measured at each grid intersecting point using a Digital Micrometer (CPM15-25DM model, Mitutoyo Co. Japan) (Fig. 3).

Calculation of the surface area and the volume of samples and statistical processing: Mean surface areas and mean volumes of limb bone containing cortical layers were calculated from thickness data. The surface areas are estimated by counting numbers of the lattices made by grids on the surface of samples (Fig. 2). The volumes are calculated by multiplying the surface area by the thickness. Mean cortical layer thicknesses, surface areas, and sample volumes were determined statistically using the Student's $t$-test.

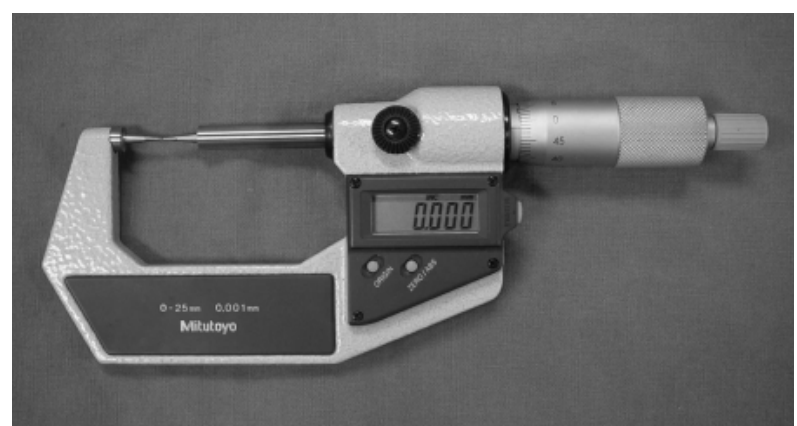

Fig. 3. Digital micrometer(CPM15-25DM model, Mitutoyo Co. Japan).

Cross section of limb bones: Diaphyses of limb bones without epiphyses were cross sectioned at $2 \mathrm{~cm}$ intervals and photographed to survey morphology of sections of bovine long bones.

\section{RESULTS}

Cortical layer thickness: The practically useful portion was $40-60 \%$ of the original length of the provided bone including the epiphyses (Table 1). The longest original bone was femur and the shortest humerus. The largest and longest usable diaphysis containing cortical layer as compared with original bone dimensions was from tibia and the 
Table 1. Length of the original bone and the practically useful cortical diaphysis, and its content rate of cortical bone in bovine limbs

\begin{tabular}{cccc}
\hline & $\begin{array}{c}\text { Original bone } \\
\text { length }(\mathrm{cm})\end{array}$ & $\begin{array}{c}\text { Practically useful } \\
\text { length }(\mathrm{cm}) \text { of cortical } \\
\text { diaphysis }\end{array}$ & $\begin{array}{c}\text { Content rate of } \\
\text { cortical bone }\end{array}$ \\
\hline Humerus & $32 \pm 3.5$ & $14.7 \pm 2.3$ & $40.6 \%$ \\
Radius & $32 \pm 3.3$ & $19.0 \pm 2.6$ & $59.4 \%$ \\
Femur & $40 \pm 3.7$ & $19.0 \pm 3.2$ & $47.5 \%$ \\
Tibia & $38 \pm 3.3$ & $23.0 \pm 3.1$ & $60.5 \%$ \\
\hline
\end{tabular}

Mean \pm SD.

Table 2. P-values by student $t$-test between the limbs

\begin{tabular}{ccccc}
\hline Volume & Surface area & & & \\
& Humerus & Radius & Femur & Tibia \\
\hline Humerus & & 0.050 & 0.0003 & 0.001 \\
Radius & 0.038 & & 0.037 & 0.047 \\
Femur & 0.010 & 0.032 & & 0.754 \\
Tibia & 0.001 & 0.007 & 0.744 & \\
\hline
\end{tabular}

smallest and shortest was from humerus. The amount of cortical bone content in the radius and tibia, distal from the body, was higher than that in humerus and femur, proximal from the body (Table 1).

Measurement data of cortical layers in $1 \mathrm{~cm}$ intervals for humerus, radius, femur and tibia are depicted in Figs. 4, 5, 6 and 7 using chiaroscuro diagrams. The thickest portion of cortical layer was concentrated around the distal caudal humerus, proximal medial and lateral midshaft of the radius, caudomedial midshaft and lateral midshaft of the femur, and tibial medial and lateral midshafts.

The surface area and volume of sample and statistical processing: Surface areas containing cortical layer are described in Fig. 8. Mean surface areas were $295.8 \pm 8.93$ $\mathrm{cm}^{2}$ in femur (the broadest), $290.0 \pm 30.44 \mathrm{~cm}^{2}$ in tibia, $229.2 \pm 43.31 \mathrm{~cm}^{2}$ in radius, and $187.4 \pm 15.44 \mathrm{~cm}^{2}$ in humerus. Volumes containing cortical layer are described in Fig. 9. Mean volume was $220.45 \pm 22.73 \mathrm{~cm}^{3}$ in femur (the largest), $214.89 \pm 20.05 \mathrm{~cm}^{3}$ in tibia, $166.26 \pm 20.02$ $\mathrm{cm}^{3}$ in radius and $149.42 \pm 15.35 \mathrm{~cm}^{3}$ in humerus. Surface areas and volumes containing cortical layer were significantly different $(\mathrm{P}<0.05)$, though the femur and tibia were similar (Table 2).

The thicknesses of cortical layers are described in Fig. 10. Mean cortical thickness was $7.98 \pm 0.54 \mathrm{~mm}$ in the humerus (the thickest), $7.49 \pm 0.78 \mathrm{~mm}$ in femur, $7.42 \pm 0.69 \mathrm{~mm}$ in radius and $7.39 \pm 0.27 \mathrm{~mm}$ in tibia. No significant difference in cortical layer mean thickness was observed between limb bones.

Cross section of limb bones: Cross sections of samples at $2 \mathrm{~cm}$ intervals were photographed and are arranged in Fig. 11. In the forelimb, the cortical layers thickened in distal sections in the humerus and in proximal sections in the radius, and were concentrated at around the elbow joint. In hindlimbs, for both femur and tibia, the thickest cortical layers were concentrated in midshaft sections and thinned toward metaphyses. The shape of cross-sectioned long bone was generally round to oval at midshaft for the humerus, radius, femur and tibia, however in the metaphyses of long bones, each bone had a differently shaped cross section. The proximal radius appeared half moon in shape and the proximal femur appeared trapezoid. The proximal tibia appeared triangular and the distal tibia rectangular. The proximal humerus containing the thickest cortical layer appeared oval and the center of the tibial midshaft containing the broadest surface area and the largest volume appeared almost triangular.

\section{DISCUSSION}

The distributions and thicknesses of cortical bone in bovine limbs differed, and their sections showed various shapes and volumes. These differences depend on species and biomechanics [9]. In this study, the distribution of volume of cortical layers in limbs was femur $>$ tibia $>$ radius $>$ humerus in order of quantity. However, Kim [9] reported that the strength of limb follows the ascending order radius $>$ tibia $>$ femur $>$ humerus. Because, in this study, the surfaces and volumes of the cortical layers of femurs and tibiae showed no significant difference and the ulna in the forelimb and the fibula in the hindlimb were not included, the order of precedence between volume of cortical layers and limb strength may appears discordant. Nevertheless, cortical layer volume is considered to be closely connected with bone strength. Kim [9] reported that the strength of limb bone is closely related to attached muscles and the angle between a limb and the ground. Kim also reported that limb bone strength is intensely affected by the capacity to withstanding load or attached muscles. Moreover, the results of the present study suggest that these factors also affect cortical layer volume.

The thickest portion of cortical bone was found in the dis- 


\section{$\mathrm{H}$ : Humerus}

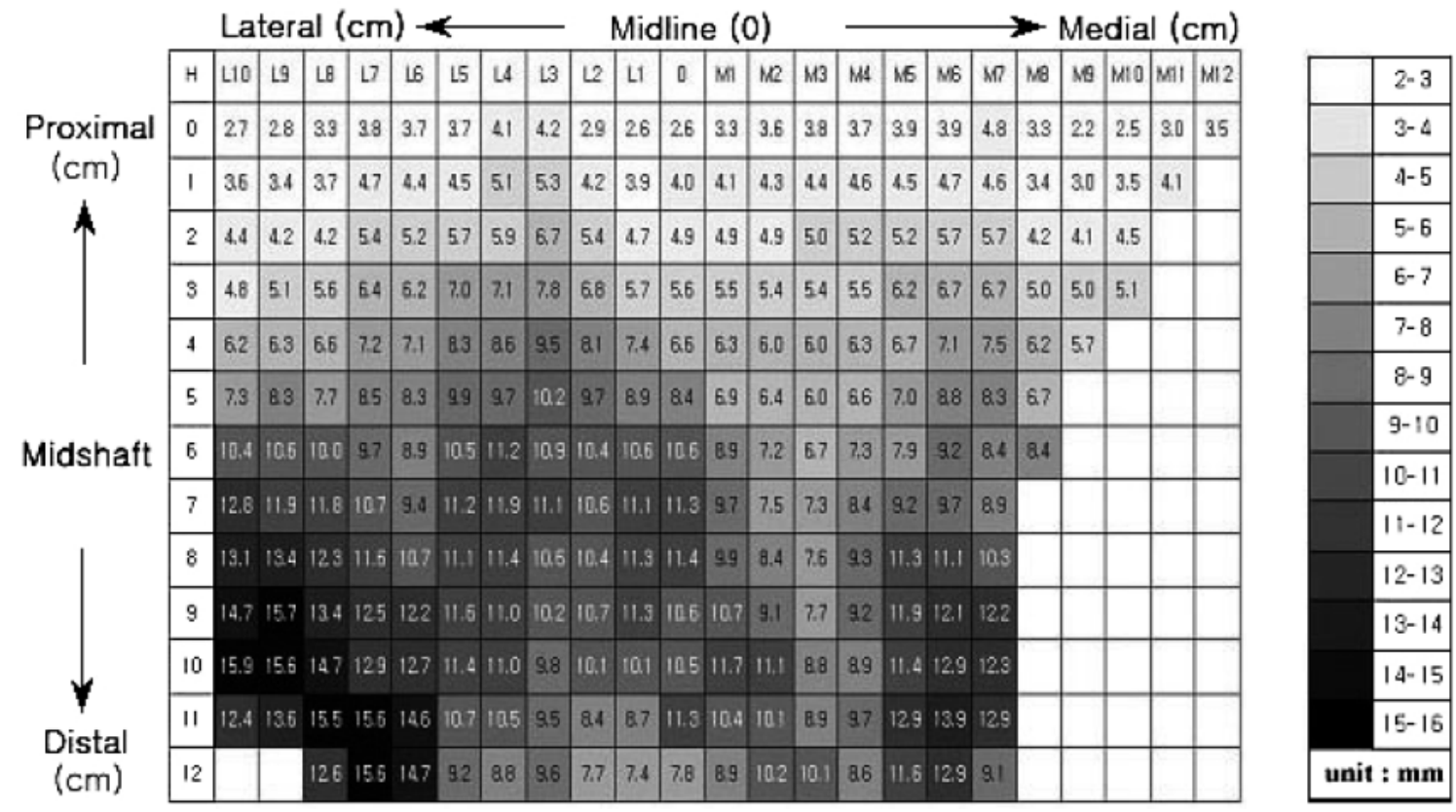

Fig. 4. Distribution diagram map of cortical bone thickness in bovine humerus.

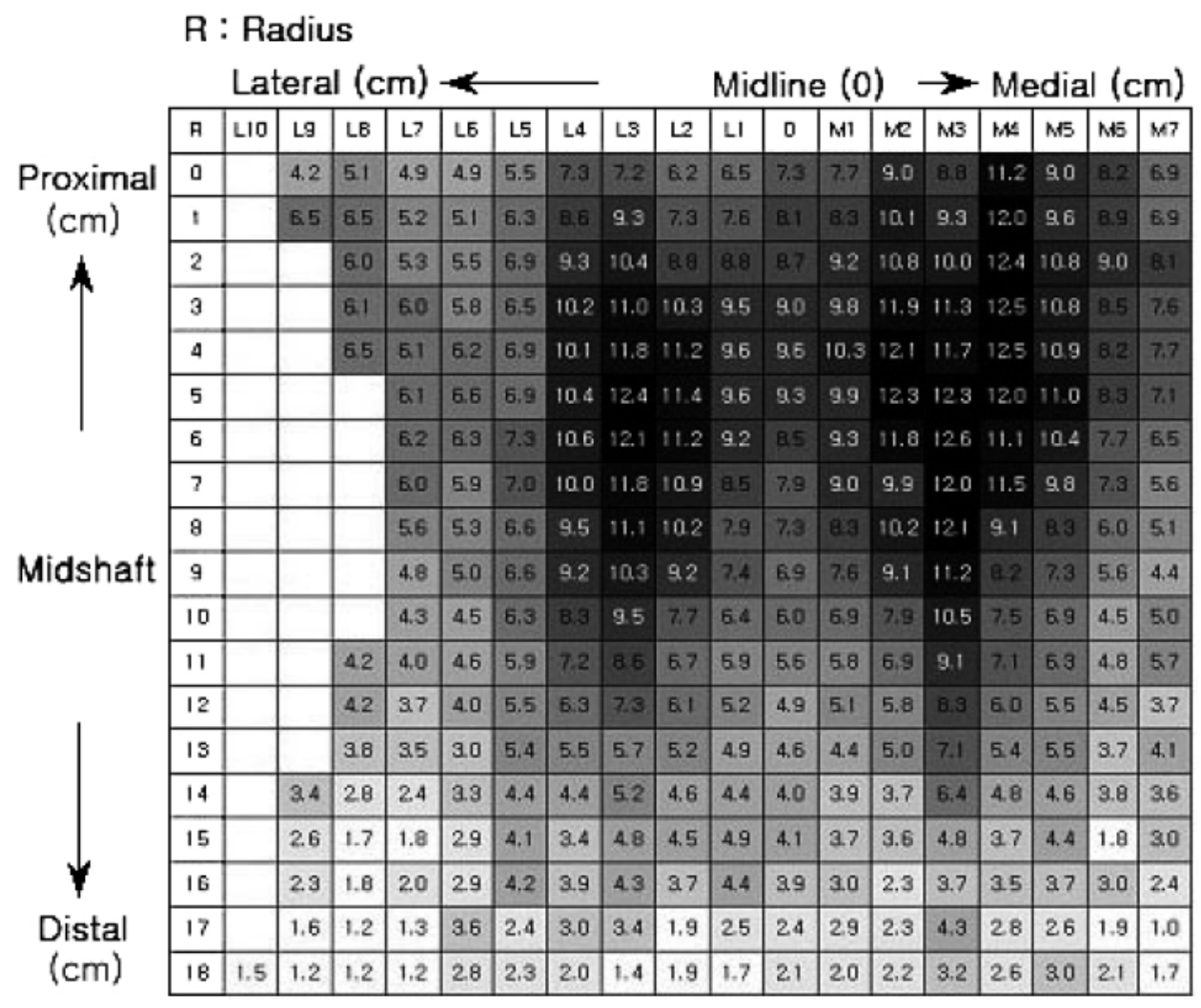

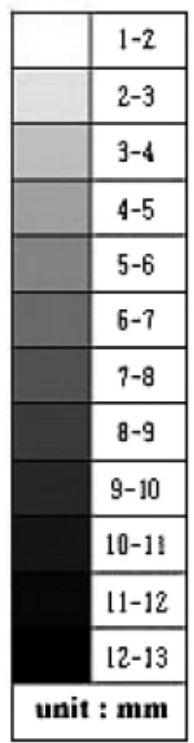

Fig. 5. Distribution diagram map of cortical bone thickness in bovine radius. 

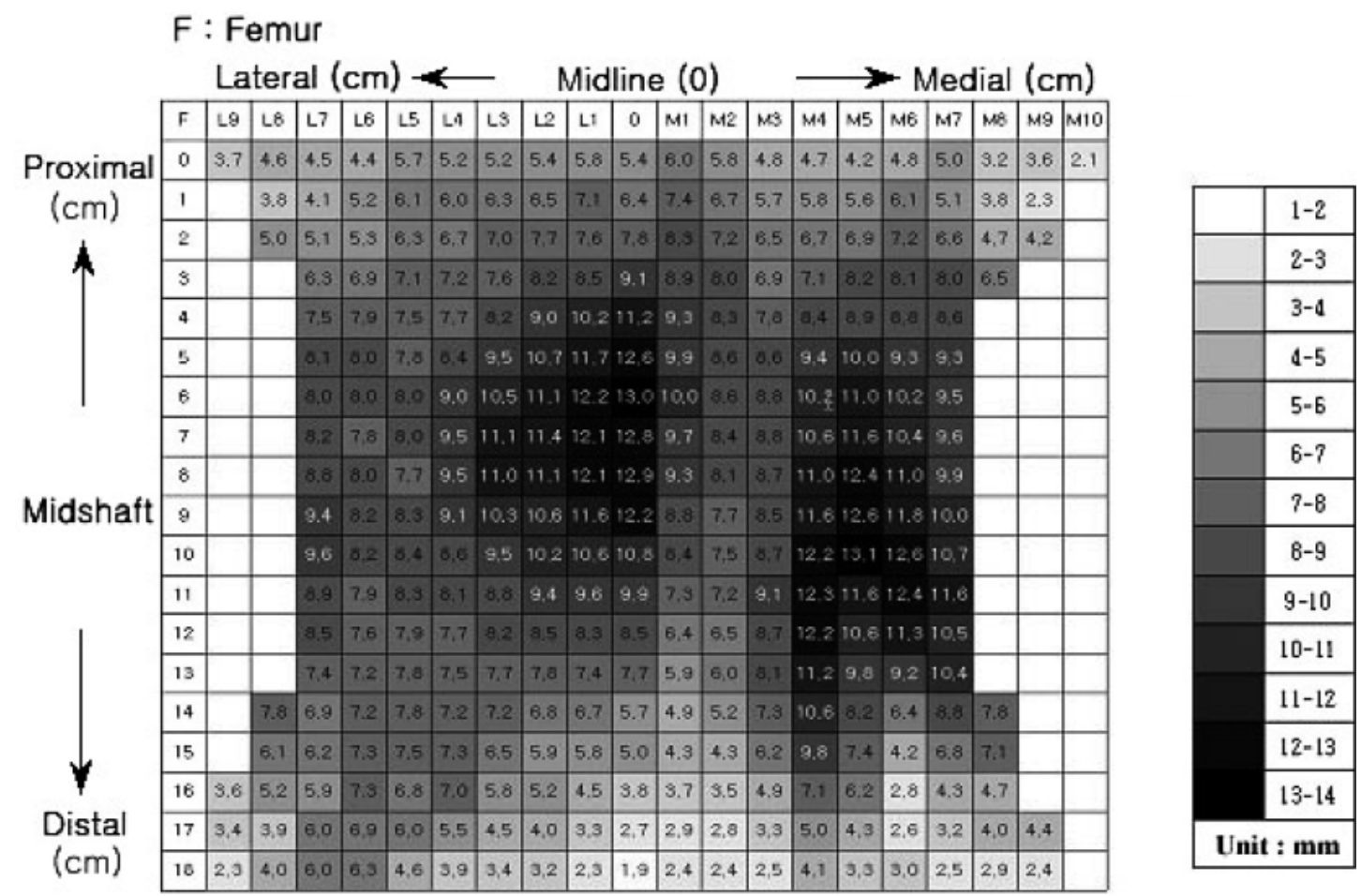

Fig. 6. Distribution diagram map of cortical bone thickness in bovine femur.

\section{T : Tibia}

Lateral $(\mathrm{cm}) \leftarrow \quad$ Midline $(0)$

Medial (cm)

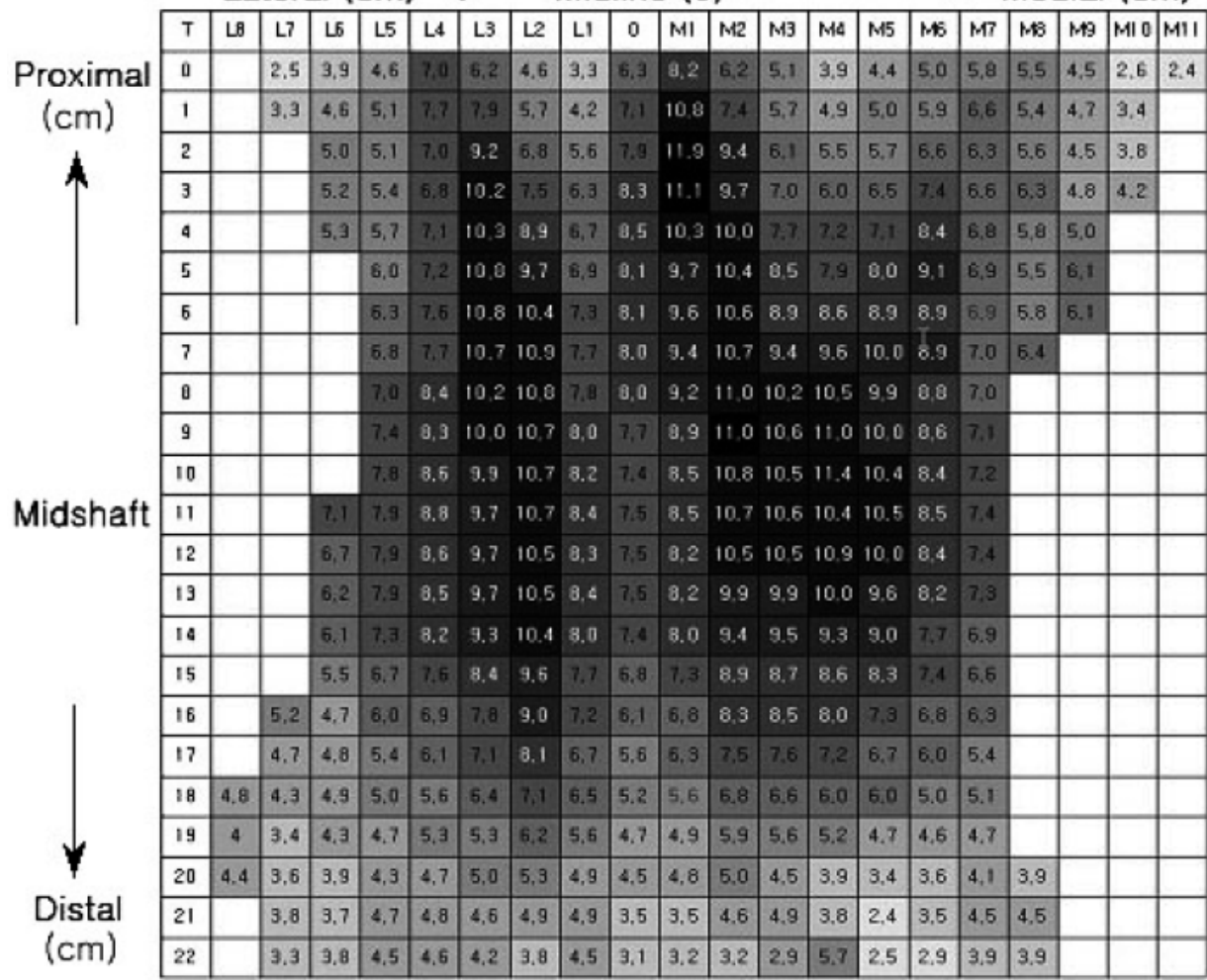

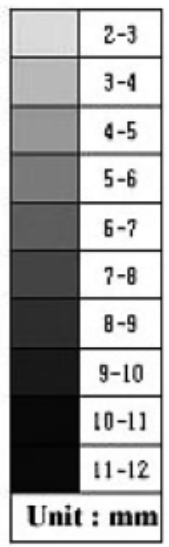

Fig. 7. Distribution diagram map of cortical bone thickness in bovine tibia. 


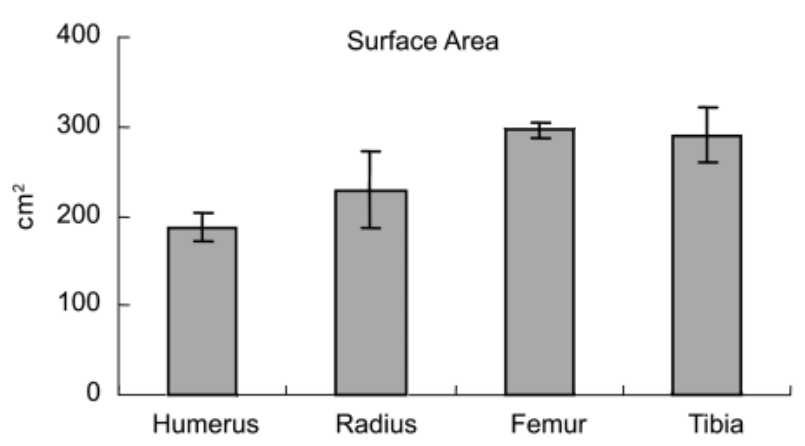

Fig. 8. Mean surface area of cortical bone in bovine limbs.

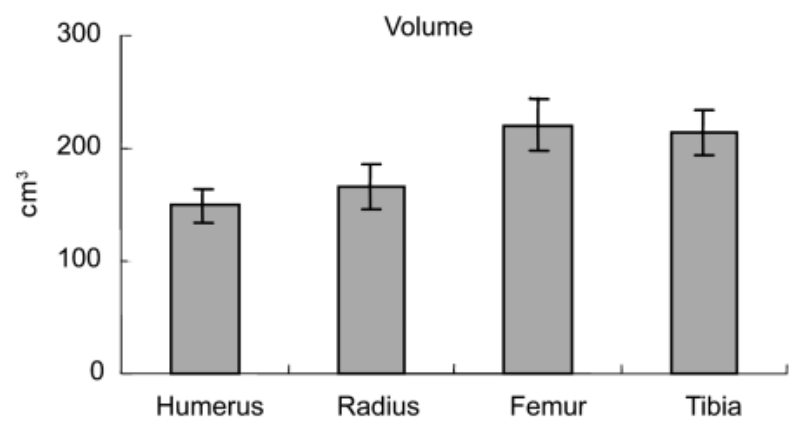

Fig. 9. Mean volume of cortical bone in bovine limbs.

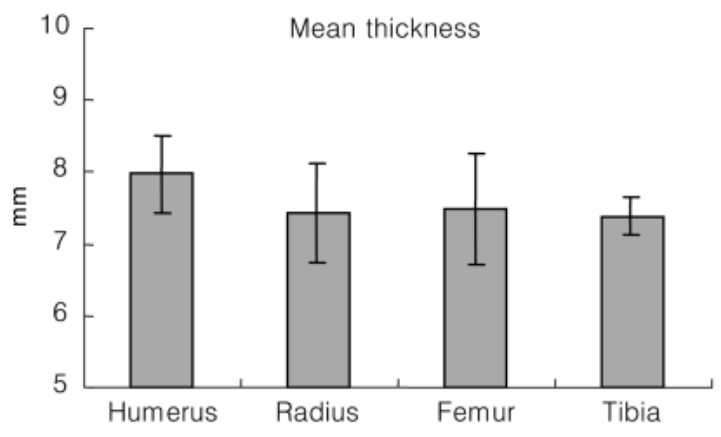

Fig. 10. Mean thickness of cortical bone in bovine limbs.

tal caudal portion of the humerus and in the caudal and craniolateral portion of the femur, which were proximal from the body, and in the shaft of the diaphyses of radius and tibia, which were distal from the body. Humerus and femur, proximal from the body, had the thickest cortical layer in the caudal bone region, which was attached by abundant muscles. On the other hand, the antebrachium (radius) and crus (tibia), which were distal from the body have thinner muscles than the humerus and femur, had thickest cortical bone at the medial and lateral part of bone rather than at the caudal region. In view of our results, the attached muscles on bones are considered to be a major factor that determines the constitution of the cortical layer in limb bone. Radius and tibia, distal from the body, had relatively large cortical portions (Table 1), meaning that they had relatively less cancel-
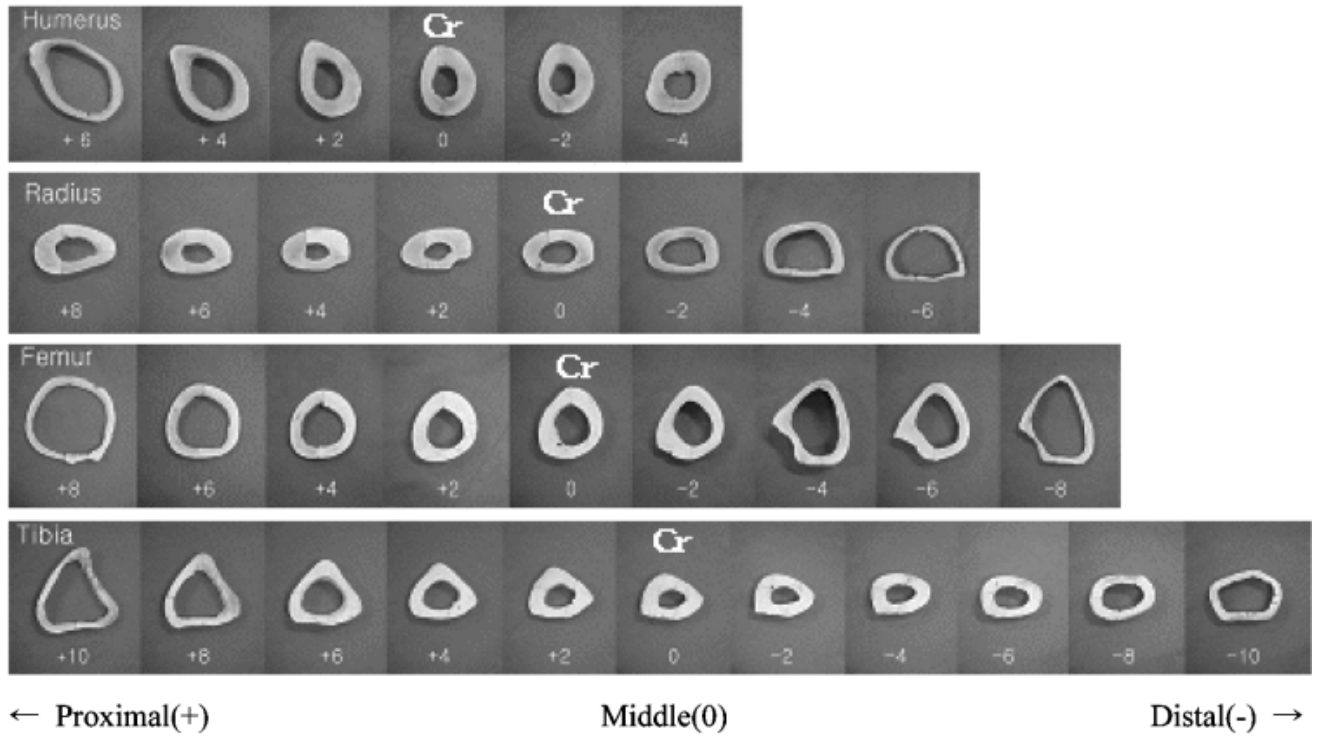

$\mathrm{Cr}$ : cranial, Numbers : distance $(\mathrm{cm})$ from the center

Fig. 11. The photographs of cross sections arranged by $2 \mathrm{~cm}$ intervals. 
lous bone in short articular lamella and a relatively long diaphysis containing cortical layer than humerus and femur, proximal from the body. This correlation explains the strength and large cortical volume of the radius and tibia.

The distal caudal humerus and proximal medial and lateral shaft of the radius, in the forelimb, had the thickest cortical layer, which was around the elbow joint. It compared with that of the distal femur and proximal tibia in the hindlimb, around the stifle joint, which didn't have the thickest cortical layer. The hindlimb and forelimb showed different cortical layer distributions; in the hindlimb it was concentrated in the center of the diaphysis in the femur and tibia. The thickest portion of cortical layer was concentrated at the cranolateral and caudomedial shafts of the diaphysis in the femur and at the lateral and cranomedial tibia. This difference in the locations of thickest portions in forelimb and hindlimb was attributed to the femur and tibia having a relatively larger surface area and a much greater volume of cortical bone than the humerus and radius, respectively, and because the normal angle of the joint at the stifle $\left(130^{\circ}\right)$ differed from that at the elbow $\left(140^{\circ}\right)$ [8]. The surface areas and volumes of cortical bone in femur and tibia showed no significant difference. These different distributions of cortical layers in forelimb and hindlimb were attributed to different weight bearing.

In cross section of limb bones appeared almost oval to round at midshaft for all samples, whereas in metaphyses, various shape were observed, e.g., triangular, rectangular, and trapezoid (Fig. 11). The thickest sections of cortical layer were at the distal humerus, the proximal radius, and the midshaft of femur and tibia, and these all were oval to round in shape. These cross sectional findings were appeared to be consistent with the distribution of cortical bone presented on Figs. 4-7. Many researchers reported that bone structural geometry or bone mineral density was affected by biomechanical loading $[4,6,10,13]$. It may be assumed that the thicker cortical portions represented on this study sustained the greater biomechanical loadings.

In terms of the presentation of data used in this study, the chiaroscuro diagrams of cortical layer distribution and the photograph of the cross sections of each limb bone, could help clinicians or researchers more effectively use as a graft from bovine limb bone or make cortical bone-based plates and screws for internal fixateurs in orthopedics.

ACKNOWLEGMENT. This study was supported by 2 nd stage Brain Korea 21 project in 2006.

\section{REFERENCES}

1. Badoux, D. M. 1975. General biostatics and biomechanics. pp. 48-83. In: Sisson and Grossman's the Anatomy of the Domestic Animals (Getty, R. ed.), WB Saunders co., Philadelphia.

2. Brinker, W. O. and Olmstead, M. L., Sumner-Smith, G. and Prieur, W. D. 1998. Manual of Internal Fixation in Small Animals, 2nd ed., Springer, New York.
3. Burwell, R. G. 1994. History of bone grafting and bone substitutes with special reference to osteogenic induction. pp. 39-42. In: Bone Grafts, Derivatives and Substitutes (Urist, M. R., O'Conner, B. T., and Burwell, R. G. eds.), Butterworth-Heinemann Ltd., Oxford.

4. Carter, D. R., van der Meulen, M. C. and Beaupre, G. S. 1996. Mechanical factors in bone growth and development. Bone 18: 5-10.

5. Denny, H. R. and Butterworth, S. J. 2000. A Guide to Canine and Feline Orthopaedic Surgery, 4th ed., Blackwell Science, Hong Kong.

6 Fritton, J. C., Myers, E. R., Wright, T. M. and van der Meulen, M. C. H. 2005. Loading induces site-specific increases in mineral content assessed by microcomputed tomography of the mouse tibia. Bone 36: 1030-1038.

7. Fyhrie, D. P. and Schaffler, M. B. 1995. The adaptation of bone apparent density to applied load. J. Biomech. 28: 135146.

8. Greenough, P. R., MacCallum, F. J. and Weaver, A. D. 1997. Lameness in Cattle, 3rd ed., WB Saunders Co., Philadelphia.

9. Kim, N. S., Hwang, E. H., Choi, S. J., Jung, I. S., Choi, E. K. and Choi, I. H. 2003. Biomechanical properties of cortical bone in bovine long bones. J. Vet. Clin. 20: 345-350.

10. Lai, Y. M., Qin, L., Hung, V. W. Y. and Chan, K. M. 2005. Regional differences in cortical bone mineral density in the weight-bearing long bone shaft-A pQCT study. Bone 36: 465-471.

11. Lindholm, T. S., Nilsson, O. S. and Lindholm, T. C. 1982. Extraskeletal and intraskeletal new bone formation induced by demineralized bone matrix combined with bone marrow cells. Clin. Orthop. Relat. Res. 171: 251-255.

12. Martin, R. B. and Atkinson, P. J. 1977. Age and sex-related changes in the structure and strength of the human femoral shaft. J. Biomech. 10: 233-231.

13. Petit, M. A., Beck, T. J., Lin, H. M., Bentley, C., Legro, R. S. and Lloyd, T. 2004. Femoral bone structural geometry adapts to mechanical loading and is influenced by sex steroids: The Penn State Young Women's Health Study. Bone 35: 750-759.

14. Poumarat, G. and Squire, P. 1993. Comparison of mechanical properties of human, bovine bone and new processed bone xenograft. J. Biomech. 14: 337-340.

15. Roe, S. 2003. Internal fracture fixation. pp. 1798-1891. In: Textbook of Small Animal Surgery, 3rd ed. (Slatter, D. ed.), WB Saunders Co., Philadelphia.

16. Rokkanen, P. U., Bostman, O., Hirvensalo, E., Makela, E. A., Partio, E. K., Patiala, H., Vainionpaa, S. I., Vihtonen, K. and Tormala, P. 2000. Bioabsorbable fixation in orthopaedic surgery and traumatology. Biomaterials 21: 2607-2613.

17. Tuominen, T., Jamsa, T., Tuukkanen, J., Marttinen, A., Lindholm, T. S. and Jalovaara, P. 2001. Bovine bone implant with bovine bone morphogenetic protein in healing a canine ulnar defect. Int. Orthop. 25: 5-8.

18. Urist, M. R. 1965. Bone formation by autoinduction. Science 150: 893-899.

19. Williams, J. L., Eick, J. D. and Schmidt, T. L. 2001. Tensile properties of the physis vary with anatomic location, thickness, strain rate and age. J. Orthop. Res. 19: 1043-1048.

20. Zioupos, P. and Currey, J. D. 1998. Changes in the stiffness, strength, and toughness of human cortical bone with age. Bone 22: $57-66$. 